\title{
Correlation Between Microstructures and Tensile Properties of Strain-Based API X60 Pipeline Steels
}

\author{
HYO KYUNG SUNG, DONG HO LEE, SUNGHAK LEE, HYOUNG SEOP KIM, \\ YUNJO RO, CHANG SUN LEE, BYOUNGCHUL HWANG, and SANG YONG SHIN
}

\begin{abstract}
The correlation between the microstructures and tensile properties of strain-based American Petroleum Institute (API) X60 pipeline steels was investigated. Eight types of strain-based API $\mathrm{X} 60$ pipeline steels were fabricated by varying the chemical compositions, such as $\mathrm{C}, \mathrm{Ni}, \mathrm{Cr}$, and $\mathrm{Mo}$, and the finish cooling temperatures, such as single-phase and dual-phase regions. In the $4 \mathrm{~N}$ and $5 \mathrm{C}$ steels, the volume fractions of bainitic ferrite $(\mathrm{BF})$ and the secondary phases increased with the increasing $\mathrm{C}$ and adding $\mathrm{Cr}$ instead of $\mathrm{Ni}$. In the $5 \mathrm{C}$ and $6 \mathrm{NC}$ steels, the volume fractions of acicular ferrite (AF) and $\mathrm{BF}$ decreased with increasing $\mathrm{C}$ and adding $\mathrm{Ni}$, whereas the volume fractions of polygonal ferrite $(\mathrm{PF})$ and the secondary phases increased. In the $6 \mathrm{NC}$ and $6 \mathrm{NM}$ steels, the volume fraction of $\mathrm{BF}$ was increased by adding Mo instead of $\mathrm{Cr}$, whereas the volume fractions of PF and the secondary phases decreased. In the steels rolled in the single-phase region, the volume fraction of polygonal ferrite ranged from 40 to $60 \mathrm{pct}$ and the volume fraction of AF ranged from 20 to 40 pct. In the steels rolled in the dual-phase region, however, the volume fraction of PF was more than 70 pct and the volume fraction of AF was below 20 pct. The strength of the steels with a high volume fraction of AF was higher than those of the steels with a high volume fraction of PF, whereas the yield point elongation and the strain hardening exponent were opposite. The uniform elongation after the thermal aging process decreased with increasing volume fraction of PF, whereas the uniform elongation increased with increasing volume fraction of AF. The strain hardening exponent increased with increasing volume fraction of $\mathrm{PF}$, but decreased with increasing volume fraction of $\mathrm{AF}$ and effective grain size.
\end{abstract}

DOI: $10.1007 / \mathrm{s} 11661-016-3453-3$

(C) The Minerals, Metals \& Materials Society and ASM International 2016

\section{INTRODUCTION}

To transport crude oil and natural gas more efficiently from the areas of production to areas of consumption, many studies have examined ways developing high strength and high toughness pipeline steels with excellent fracture resistance properties against sudden deformation and fracture by heavy storms, earthquakes, and seismic sea waves. ${ }^{[1-3]}$ Pipeline steels are used after the piping and corrosion-resistant coating processes, in which uniform elongation and the deformability decrease because of the strain aging

HYO KYUNG SUNG, Assistant Professor, is with the Department of Materials Science and Engineering, ReCAPT Gyeongsang National University, Jinju 52828, Korea. DONG HO LEE, Research Assistant, and SUNGHAK LEE and HYOUNG SEOP KIM, Professors, are with the Center for Advanced Aerospace Materials, Pohang University of Science and Technology, Pohang 37673, Korea. YUNJO RO, Researcher, and CHANG SUN LEE, Senior Vice President, are with the POSCOA Research Group Team, Technical Research Laboratories, POSCO, Gwangyang, 57807, Korea. BYOUNGCHUL HWANG, Assistant Professor, is with the Department of Materials Science and Engineering, Seoul National University of Science and Technology, Seoul, 01811, Korea. SANG YONG SHIN, Assistant Professor, is with the School of Materials Science and Engineering, University of Ulsan, Ulsan, 44610, Korea. Contact e-mail: sshin@ ulsan.ac.kr

Manuscript submitted July 16, 2015.

Article published online March 22, 2016 phenomenon. ${ }^{[4-6]}$ To restrain the strain aging phenomenon during the piping and corrosion-resistant coating processes, many studies have been conducted to reduce the number of carbon atoms in ferrite and to form more cementite ${ }^{[7-9]}$

Shigesato et al..$^{[7]}$ reported that cementites were distributed uniformly when $\mathrm{Cr}$ was added in American Petroleum Institute (API) X80 pipeline steels. When Mo was added to the API X80 pipeline steels, however, the cementites were not distributed uniformly but were almost formed in the narrow space of the bainite lath; hence, the uniform elongation and deformability of the API X80 pipeline steels decreased. ${ }^{[7]}$ Hara et al. ${ }^{[8]}$ reported that continuous yielding behaviors occurred without a rapid decrease in uniform elongation when $\mathrm{Cr}$, a strong carbide-forming element, was added to the API X80 pipeline steels. Shinohara et al. ${ }^{[9]}$ reported that the uniform elongation of the bainitic API X80 and X100 pipeline steels increased with increasing the volume fraction of polygonal ferrite (PF) formed by the mild accelerated cooling processes. The recently developed strain-based pipeline steels exhibited discontinuous yielding behavior because the main microstructure was polygonal ferrite and the volume fraction of hard secondary phases was low. ${ }^{[10,11]}$ The tensile properties of the API pipeline steels are affected by piping and corrosion-resistant coating processes. Therefore, it 
is important to examine the effects of the microstructures on the tensile properties, such as the strength, elongation, and strain hardening exponent in the ferritic strain-based pipeline steels before and after piping and corrosion-resistant coating processes.

In this study, eight types of the strain-based API X60 pipeline steels were fabricated by varying the chemical compositions and finish rolling temperatures, and their microstructural factors were analyzed. In the chemical compositions, carbide-forming and austenite-stabilizing elements, such as $\mathrm{C}$ and $\mathrm{Ni}$, and ferrite-stabilizing elements, such as $\mathrm{Cr}$ and Mo, were controlled. ${ }^{[12-16]}$ Two types of finish rolling temperatures were used, single-phase $(\gamma)$ and dual-phase $(\gamma+\alpha)$ rolling conditions. In general, acicular ferrite $(\mathrm{AF})$ and bainitic ferrite (BF) are formed with fine carbides at the grain boundaries or in the bainitic ferrite grains by single-phase rolling conditions, whereas the polygonal ferrite is formed with fine carbides at the grain boundaries under dual-phase rolling conditions. Moreover, effective grains and grain boundary conditions, such as low- and high-angle grain boundaries, were analyzed by electron backscatter diffraction (EBSD) analysis. The tensile properties, such as strength and uniform elongation, were measured by tensile tests after piping and coating simulation processes, and the correlation between the microstructures and tensile properties of the strainbased API X60 pipeline steels were studied.

\section{EXPERIMENTAL}

Table I lists the chemical compositions of the strainbased API X60 pipeline steels and Figure 1 shows the rolling and heat treatment conditions. All the steels were austenized at $1373 \mathrm{~K}\left(1100{ }^{\circ} \mathrm{C}\right)$ for 2 hours and then rolled in single-phase region ( $\gamma$ region) or dual-phase region $(\alpha+\gamma$ region) under air-cooling conditions, in which a reduction ratio of 89 pct was given to make a plate with a final thickness of $32 \mathrm{~mm}$. For convenience, the steels rolled in the single-phase region and in the dual-phase region are referred to as '-S' and '-D' steels, respectively. After the finish rolling process, the specimens were water-cooled in a cooling rate of $15 \mathrm{~K} / \mathrm{s}$, until $773 \mathrm{~K}\left(500{ }^{\circ} \mathrm{C}\right)$, and then air-cooled to room temperature.

The steel specimens obtained from a 1/4 thickness location of the rolled plates were polished and etched in a 2 pet nital solution and the microstructures of longitudinal-transverse $(\mathrm{L}-\mathrm{T})$ planes were observed by optical and scanning electron microscope (SEM, model; S-4300E, Hitachi, Tokyo, Japan). For electron backscatter diffraction analysis, the steel specimens were polished using a colloidal silica solution after mechanical polishing. ${ }^{[17]}$ EBSD analysis (resolution: $400 \mathrm{~nm}$ ) was conducted by field emission scanning electron microscope (FE-SEM, model: S-4300SE, Hitachi, Tokyo, Japan). The EBSD measurements were carried out after micropolishing using $1 \mu \mathrm{m}$ diamond suspension and $0.25 \mu \mathrm{m}$ colloidal silica under an applied potential of $25 \mathrm{kV}$ and $0.05 \mu \mathrm{m}$ step size. The data were then interpreted by orientation imaging microscopy analysis software provided by TexSEM Laboratories, Inc. The effective grain size was measured from the EBSD analysis. The microstructures of longitudinal-transverse (L-T) planes were observed by EBSD.

The tensile specimens were obtained from a $1 / 4$ thickness location of the rolled plates. Round-type tensile specimens with a gage length of $25 \mathrm{~mm}$ and a diameter of $6 \mathrm{~mm}$ were prepared in the transverse direction according to the ASTM Standard E8/ E8m-13a. ${ }^{[18]}$ A pre-strain of 1 pct was given on tensile specimens to simulate the strain state of the piping process and the tensile tests were performed at room temperature at a strain rate of $0.003 \mathrm{~s}^{-1}$ using an Instron machine (model; 5567, Instron, USA) with a 100 $\mathrm{kN}$ capacity. The pre-strain, from 1 to 2 pct, was applied to the pipeline steel plates during the piping processes. ${ }^{[6]}$ Heat treatment at $473 \mathrm{~K}\left(200^{\circ} \mathrm{C}\right)$ for $5 \mathrm{~min}$ was given to the steel plates to simulate the epoxy coating process. From the engineering stress-engineering strain curves, the tensile properties, such as the yield strength, ultimate tensile strength, uniform elongation, yield ratio, and yielding behavior, were measured.

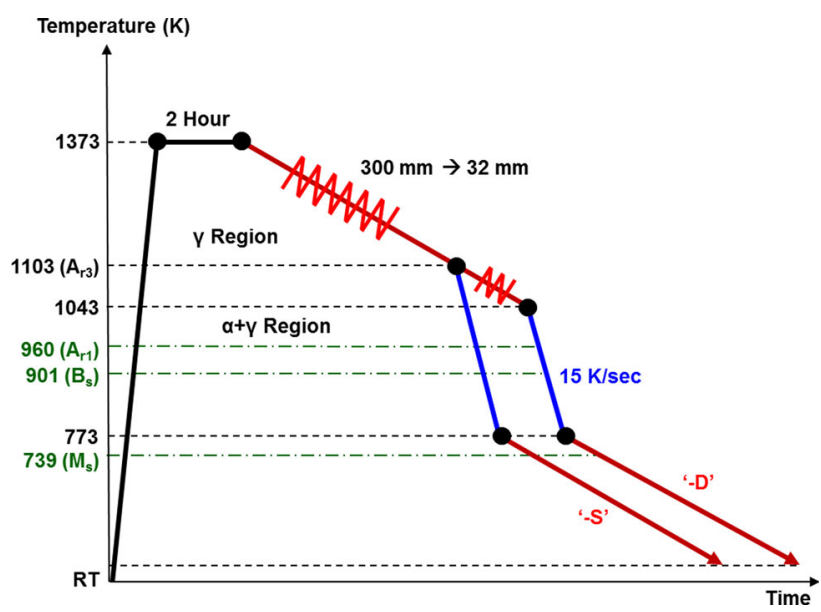

Fig. 1-Schematic diagram of the rolling and cooling conditions of the strain-based API X60 pipeline steels.

Table I. Chemical Compositions of the Strain-Based API X60 Pipeline Steels (Wt. Percent)

\begin{tabular}{llllll}
\hline Steel & $\mathrm{C}$ & $\mathrm{Ni}$ & $\mathrm{Cr}$ & $\mathrm{Mo}$ & $\mathrm{Si}+\mathrm{Mn}+\mathrm{Ti}+\mathrm{Nb}+\mathrm{P}+\mathrm{S}$ \\
\hline 4N & 0.04 & 0.3 & 0 & 0 & $<0.5$ \\
5C & 0.05 & 0 & 0.15 & 0 & \\
6NC & 0.06 & 0.1 & 0.15 & 0 & \\
6NM & 0.06 & 0.1 & 0 & 0.15 & \\
\hline
\end{tabular}



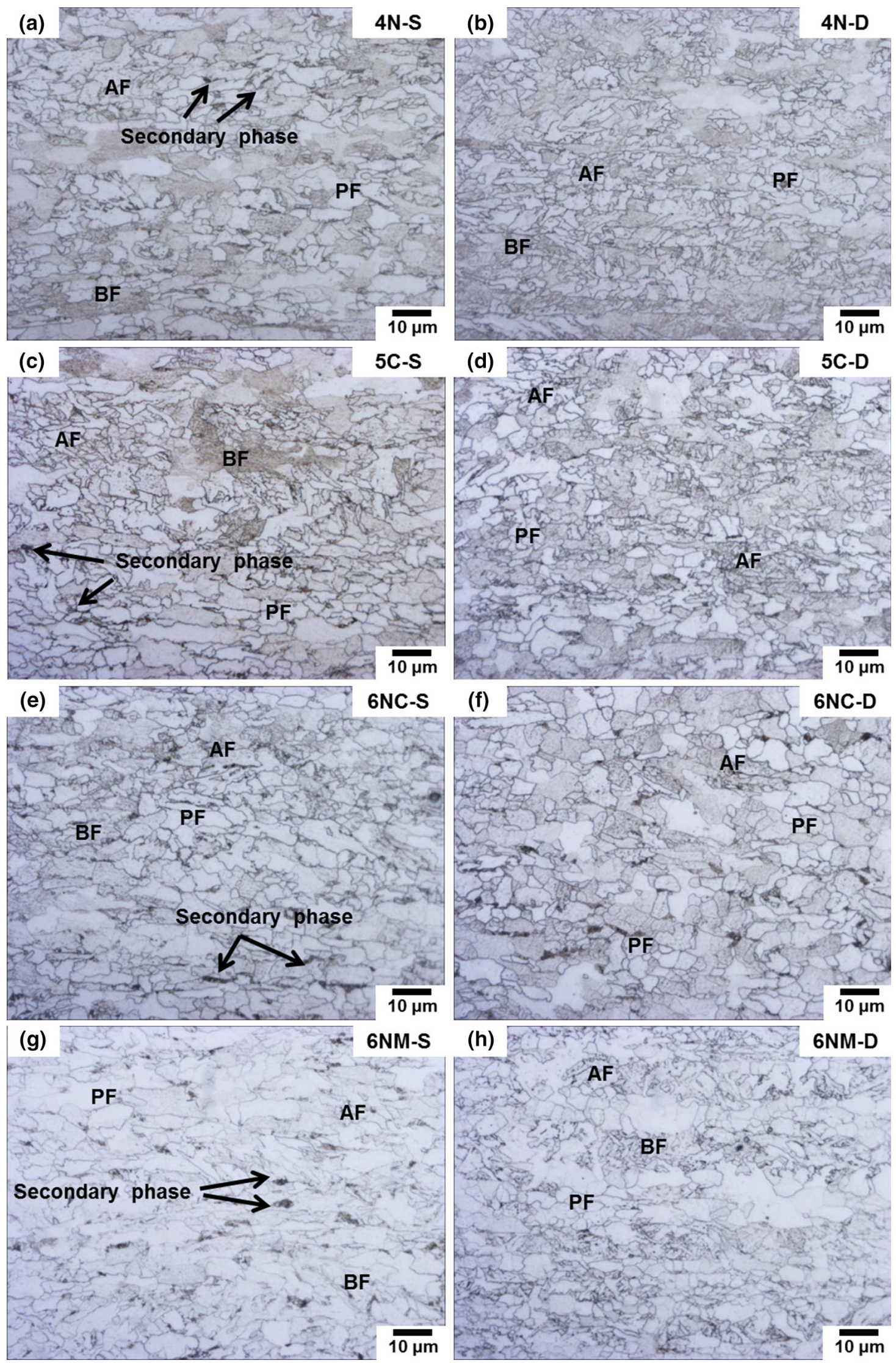

Fig. 2-Optical micrographs (L-T plane) of the nital etched $(a) 4 \mathrm{~N}-\mathrm{S},(b) 4 \mathrm{~N}-\mathrm{D},(c)$ 5C-S, $(d)$ 5C-D, $(e) 6 \mathrm{NC}-\mathrm{S},(f) 6 \mathrm{NC}-\mathrm{D},(g)$ 6NM-S, and $(h)$ 6NM-D steels. 

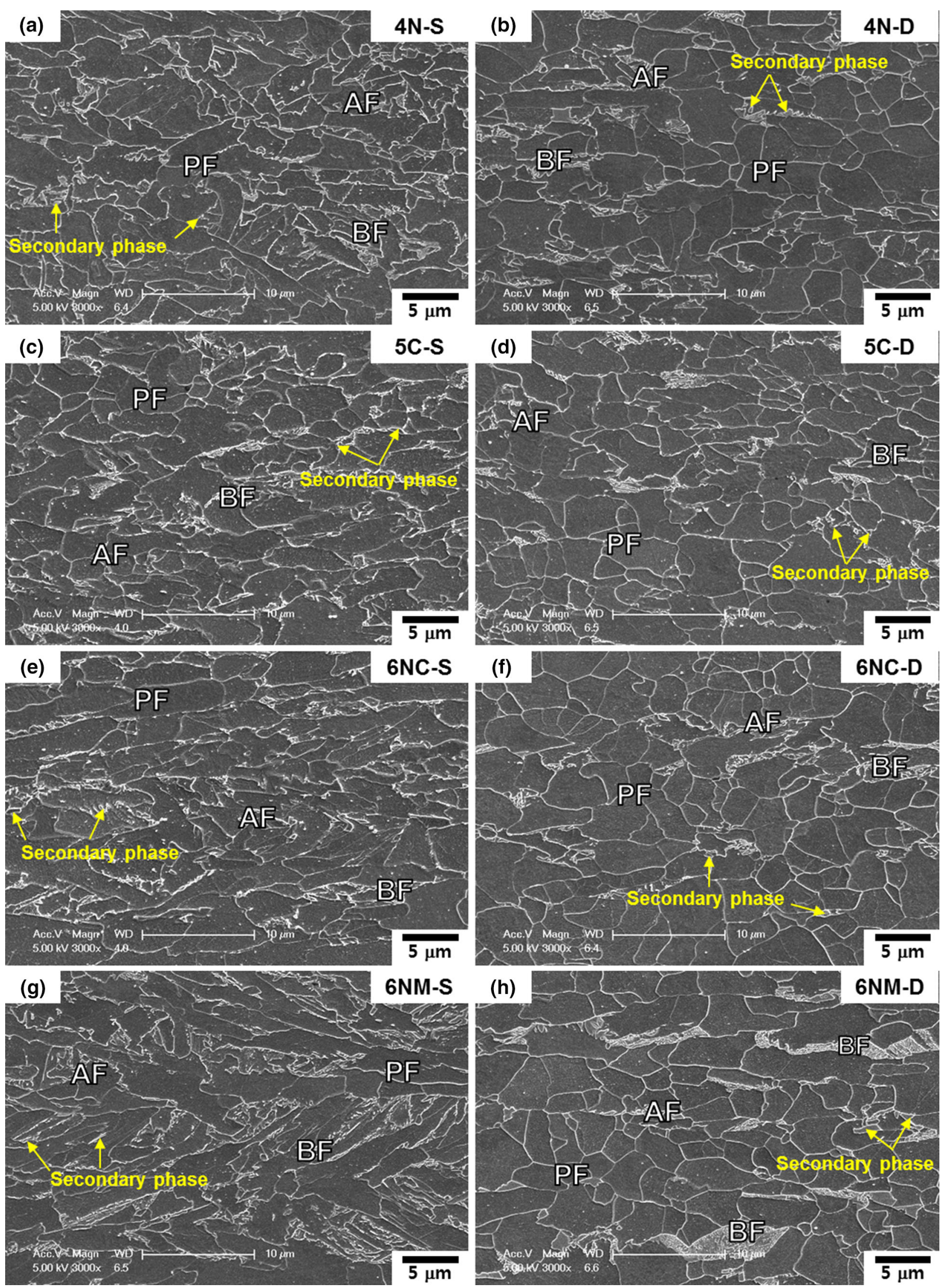

Fig. 3-SEM micrographs (L-T plane) of the nital etched $(a)$ 4N-S, $(b)$ 4N-D, $(c)$ 5C-S, (d) 5C-D, $(e)$ 6NC-S, $(f)$ 6NC-D, $(g)$ 6NM-S, and $(h)$ 6NM-D steels. 
Table II. Volume Fractions of Polygonal Ferrite, Acicular Ferrite, Bainitic Ferrite, and Secondary Phase and Effective Grain Size in the Steels

Volume Fraction (pct)

\begin{tabular}{lccccc} 
Steel & Polygonal Ferrite $(\mathrm{PF})$ & Acicular Ferrite $(\mathrm{AF})$ & Bainitic Ferrite $(\mathrm{BF})$ & Secondary Phase* & Effective Grain Size** $^{*}(\mu \mathrm{m})$ \\
\hline 4N-S & $54.8 \pm 6.4$ & $35.6 \pm 3.1$ & $8.1 \pm 0.9$ & $1.5 \pm 0.1$ & $8.9 \pm 0.7$ \\
5C-S & $56.3 \pm 7.2$ & $28.4 \pm 3.6$ & $13.2 \pm 1.8$ & $2.1 \pm 0.2$ & $7.5 \pm 0.8$ \\
6NC-S & $61.2 \pm 8.3$ & $23.5 \pm 2.7$ & $10.7 \pm 1.2$ & $4.6 \pm 0.6$ & $7.2 \pm 0.6$ \\
6NM-S & $38.2 \pm 4.6$ & $40.3 \pm 4.6$ & $17.0 \pm 2.1$ & $4.5 \pm 0.4$ & $7.4 \pm 0.6$ \\
4N-D & $80.7 \pm 9.7$ & $12.4 \pm 1.5$ & $4.1 \pm 06$ & $2.8 \pm 0.3$ & $6.4 \pm 0.6$ \\
5C-D & $70.1 \pm 8.4$ & $20.4 \pm 2.2$ & $6.5 \pm 0.8$ & $3.0 \pm 0.4$ & $5.7 \pm 0.5$ \\
6NC-D & $74.2 \pm 7.9$ & $18.8 \pm 2.1$ & $1.5 \pm 0.2$ & $5.5 \pm 0.7$ & $5.2 \pm 0.5$ \\
6NM-D & $70.9 \pm 6.5$ & $10.6 \pm 1.3$ & $14.6 \pm 1.3$ & $3.9 \pm 0.3$ & $6.6 \pm 0.7$ \\
\hline
\end{tabular}

* Secondary phases include martensite-austenite constituents and cementite. SEM.

** The effective grain size was measured from the EBSD analysis. The microstructures of longitudinal-transverse $(\mathrm{L}-\mathrm{T})$ planes were observed by

\section{RESULTS}

\section{A. Microstructures}

The microstructures of API pipeline steels are dependent on the chemical compositions and the cooling and rolling conditions, and are classified according to their morphological categories. ${ }^{[12,19-22]}$ Polygonal ferrite is formed at high temperatures and a slow cooling rate, and has an equiaxed shape nucleated from prior austenite grain boundaries and very low dislocation density. With decreasing transformation temperature or increasing rolling processes, the ferrite grains become more irregular shaped, in which the ferrite is called quasi-polygonal ferrite (QPF). Acicular ferrite has an excellent combination of strength and toughness because its grains are fine (several micrometers in size), irregular shaped, and aligned in arbitrary directions. Bainitic ferrite is generally formed at rapid cooling rates, and has high strength and low toughness because of its lath-type microstructure. Secondary phases include martensite, martensite-austenite constituents which are finely formed in regions with high carbon content.

Figures 2 and 3 show the optical and SEM microstructures of the steels, from which the volume fractions of the microstructures were measured and listed in Table II. At least five micrographs were analyzed for each of the steels, and the volume fractions of the microstructures were obtained using an image analyzer program (Sigma scan pro, Systat Software Inc., USA). In view of the equiaxed grain geometry, this type of ferrite is referred to as equiaxed or PF. It is observed in the light microscope and is characterized by very low dislocation densities and the absence of substructure. The term acicular means shaped and pointed like a needle. AF is generally characterized by fine grain size, irregular shape, and alignment in arbitrary directions. $\mathrm{BF}$ is identified depending on the presence or distribution of secondary phases as a lath-type microstructure. A subunit nucleates at an austenite grain boundary and lengthens before its growth is suppressed by plastic deformation. The steels consisted mainly of PF with a small amount of AF, BF, and secondary phases. The volume fractions of microstructures are affected by the chemical compositions and the finish rolling temperatures.

In the '-S' steels rolled in the single-phase region, the volume fraction of PF ranged from 40 to 60 pct and the volume fraction of AF ranged from 20 to 40 pct. In the $4 \mathrm{~N}-\mathrm{S}$ steel with a low $\mathrm{C}$ and high $\mathrm{Ni}$, the volume fractions of $\mathrm{BF}$ and secondary phases were 8 and 1.5 pct, respectively. In the $5 \mathrm{C}-\mathrm{S}$ steel with a medium $\mathrm{C}$ and $\mathrm{Cr}$, the volume fractions of $\mathrm{BF}$ and secondary phases were high (13 and 2.1 pct, respectively). In the 6NC-S steel with a high $\mathrm{C}, \mathrm{Cr}$, and $\mathrm{Ni}$, the volume fraction of AF was low at 23.5 pct and the volume fraction of the secondary phases was high at 4.6 pct. In the 6NM-S steel with a high $\mathrm{C}$ and Mo, the volume fraction of $\mathrm{PF}$ was low at 40 pet and the volume fractions of $\mathrm{AF}, \mathrm{BF}$, and secondary phases were high at 40,17 , and 4.5 pct, respectively.

In the '-D' steels rolled in the dual-phase region, the volume fraction of PF was over 70 pct and the volume fraction of AF was below 20 pct. The '-D' steels had fewer low-temperature transformation microstructures, such as AF and BF, than the '-S' steels. In the $4 \mathrm{~N}-\mathrm{D}$ steel, the volume fraction of PF was high (80 pct) and the volume fraction of secondary phases was low (28 pct). In the 5C-D steel, the volume fraction of PF was low (70 pct) and the volume fractions of AF, BF, and secondary phases were $20.4,6.5$, and 3 pct, respectively. In the 6NC-D steel, volume fraction of $\mathrm{BF}$ was low $(1.5 \mathrm{pct})$ and the volume fraction of secondary phases was high $(5.5 \mathrm{pct})$. In the 6NM-D steel, the volume fraction of PF was low (70.9 pct) and the volume fractions of BF and secondary phases were high (14.6 and 3.9 pct, respectively).

Figure 4 shows the inverse pole figure maps of the steels analyzed by EBSD analysis. In the inverse pole figure maps, the boundaries between the grains that showed different orientations of $15 \mathrm{deg}$ or higher were high-angle grain boundaries, which were generally considered to be effective grains. ${ }^{[23,24]}$ The effective grain size of the '-S' steels were slightly larger than those of the '-D' steels because fine PF grains with approximately $3 \mu \mathrm{m}$ were formed by the rolling processes in the dual-phase region. The effective grain size of AF in the 

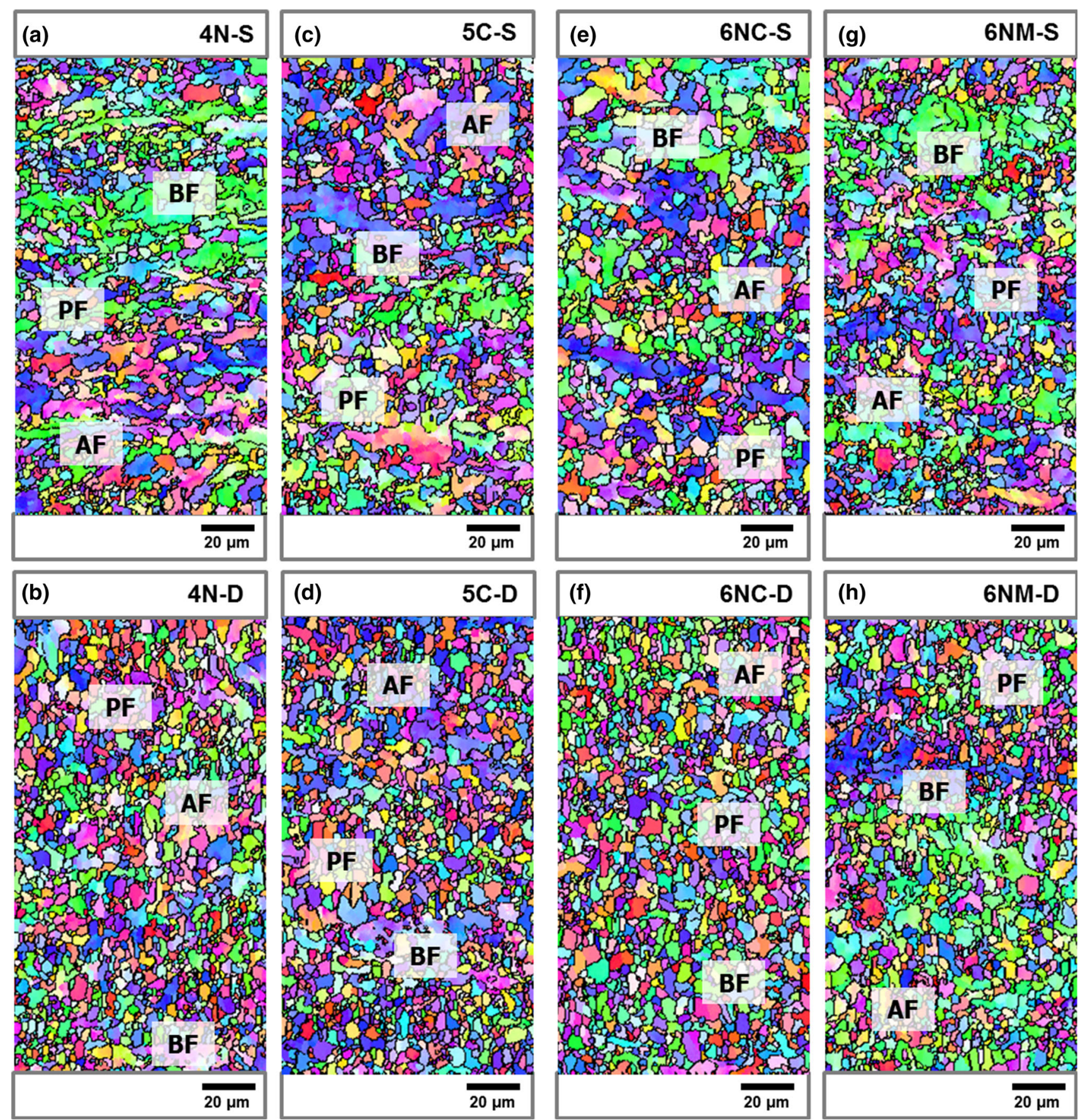

Fig. 4-EBSD images of the $(a)$ 4N-S, $(b)$ 4N-D, $(c)$ 5C-S, $(d)$ 5C-D, $(e)$ 6NC-S, $(f)$ 6NC-D, $(g)$ 6NM-S, and $(h)$ 6NM-D steels.

'-S' steels was approximately $5 \mu \mathrm{m}$, which was larger than that of PF in the '-D' steels. The '-D' steels showed band structures with elongated PF grains along the rolling direction.

\section{B. Room-Temperature Tensile Properties}

API pipeline steels are classified according to the yield strength. For example, API X60 pipeline steels have a yield strength over $60 \mathrm{ksi}(=413 \mathrm{MPa})$. Figure 5 shows the room-temperature engineering stress-engineering strain curves, from which yield strength, ultimate tensile strength, uniform elongation, total elongation, yield point elongation, yield ratio, and strain hardening exponent of the steels were measured, as listed in Table III. The 4N-S and 6NM-S steels showed continuous yielding behavior, whereas the others showed the discontinuous yielding behavior. The yield strength and ultimate tensile strength of the '-S' steels with a high volume fraction of $\mathrm{AF}$ ranged from 460 to $510 \mathrm{MPa}$ and from 550 to 590 $\mathrm{MPa}$, respectively, which were higher than those of the '-D' steels with a high volume fraction of PF. The uniform 


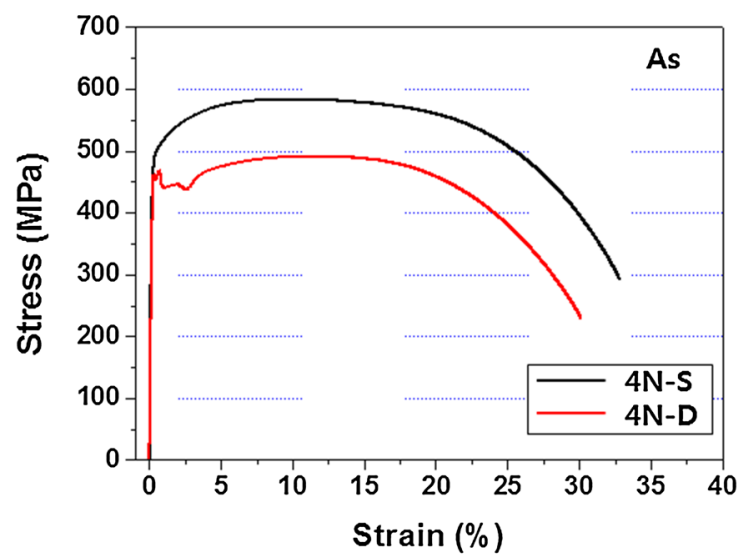

(a)

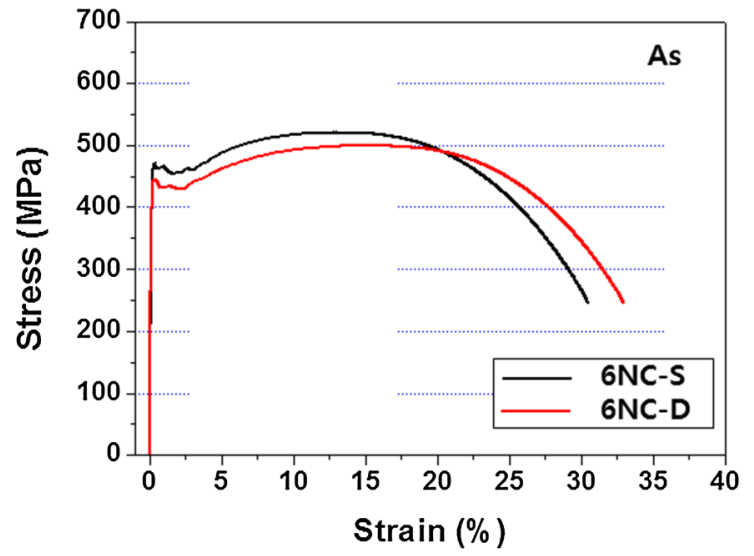

(c)

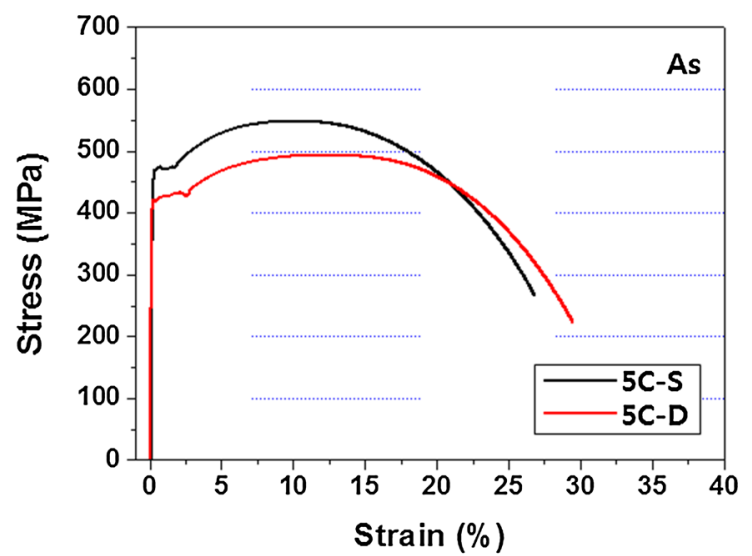

(b)

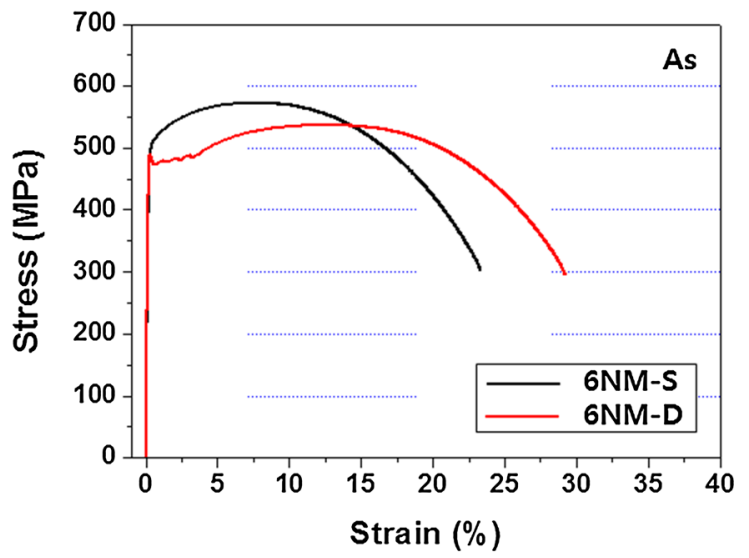

(d)

Fig. 5-Room-temperature engineering stress-engineering strain curves of the $(a) 4 \mathrm{~N},(b) 5 \mathrm{C},(c) 6 \mathrm{NC}$, and $(b) 6 \mathrm{NM}$ steels.

Table III. Room-Temperature Tensile Properties of the Steels

\begin{tabular}{|c|c|c|c|c|c|c|c|}
\hline Steel & $\begin{array}{l}\text { Yield Strength } \\
(\mathrm{MPa})\end{array}$ & $\begin{array}{l}\text { Ultimate Tensile } \\
\text { Strength }(\mathrm{MPa})\end{array}$ & $\begin{array}{l}\text { Uniform } \\
\text { Elongation } \\
\text { (pct) }\end{array}$ & $\begin{array}{c}\text { Total } \\
\text { Elongation } \\
\text { (pct) }\end{array}$ & $\begin{array}{c}\text { Yield point } \\
\text { Elongation }(\mathrm{pct})^{*}\end{array}$ & Yield Ratio & $\begin{array}{c}\text { Strain Hardening } \\
\text { Exponent }(n \text { value })^{* *}\end{array}$ \\
\hline $4 \mathrm{~N}-\mathrm{S}$ & 500 & 584 & 9.9 & 33 & $\mathrm{C}$ & 0.86 & 0.09 \\
\hline $5 \mathrm{C}-\mathrm{S}$ & 473 & 548 & 10.0 & 27 & 1.7 & 0.86 & 0.13 \\
\hline 6NC-S & 460 & 521 & 13.1 & 31 & 2.9 & 0.88 & 0.16 \\
\hline 6NM-S & 510 & 573 & 7.6 & 23 & $\mathrm{C}$ & 0.89 & 0.08 \\
\hline $4 \mathrm{~N}-\mathrm{D}$ & 437 & 489 & 16.6 & 35 & 5.1 & 0.89 & 0.17 \\
\hline 5C-D & 429 & 494 & 12.4 & 30 & 2.7 & 0.87 & 0.15 \\
\hline 6NC-D & 429 & 500 & 15.1 & 33 & 2.3 & 0.86 & 0.16 \\
\hline 6NM-D & 473 & 537 & 12.5 & 29 & 3.4 & 0.88 & 0.15 \\
\hline
\end{tabular}

* C: continuous yielding behavior.

** Calculated from true strain range, from 1 to 5 pct.

elongation of the '-S' and '-D' steels ranged from 7 to 13 pct and from 12 to 17 pct, respectively. The steels showed high total elongations of approximately $30 \mathrm{pct}$, except for the $6 \mathrm{NM}-\mathrm{S}$ steel. The yield point elongation of the '-S' steels ranged from 1.7 to 2.9 pct, which were lower than those of the '-D' steels (from 2.3 to $5.1 \mathrm{pct}$ ). The strain hardening exponent of the ' $-\mathrm{S}$ ' steels ranged from 0.09 to 0.16 pct, which were lower than those of the '-D' steels (from 0.15 to $0.17 \mathrm{pct}$ ). The yield ratios of the steels were similar.
Figure 6 shows the room-temperature engineering stress-engineering strain curves obtained from tensile tests of the specimens after 1 pct pre-strain and thermal aging at $473 \mathrm{~K}\left(200^{\circ} \mathrm{C}\right)$, from which the tensile properties were measured as shown in Table IV. All the steel specimens showed discontinuous yielding behavior. The yield strength and ultimate tensile strength of the '-S' steels after 1 pct pre-strain and thermal aging at $473 \mathrm{~K}\left(200{ }^{\circ} \mathrm{C}\right)$ ranged from 445 to $541 \mathrm{MPa}$ and from 515 to $576 \mathrm{MPa}$, respectively, 


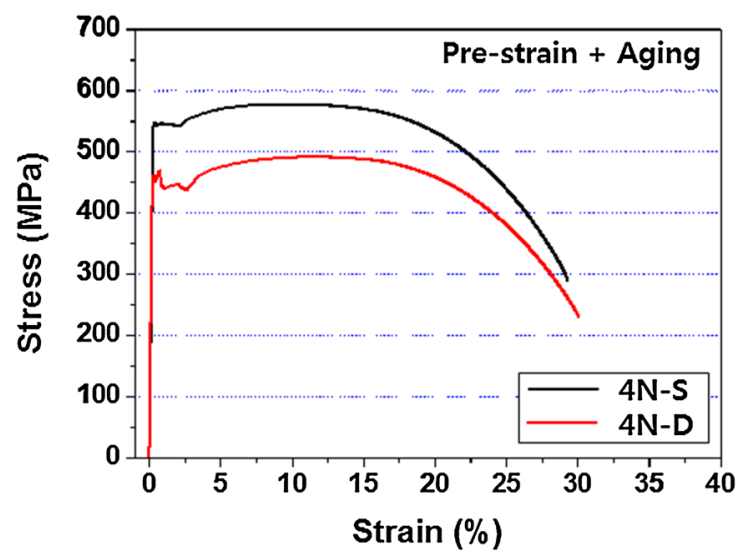

(a)

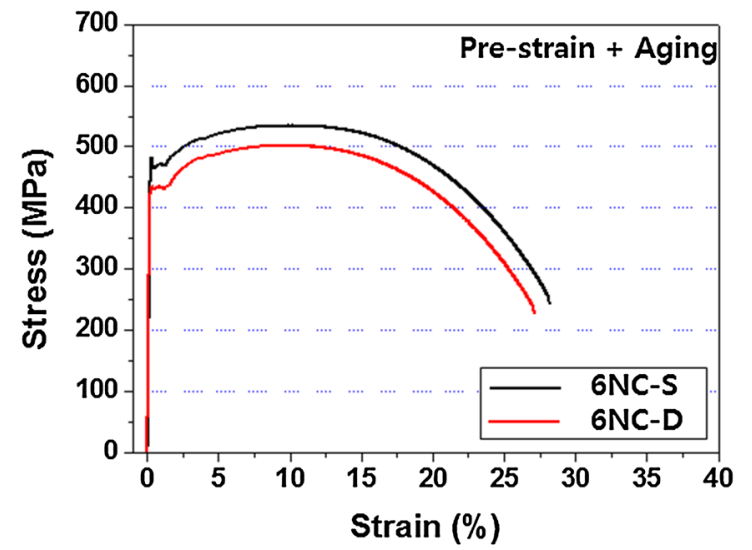

(c)

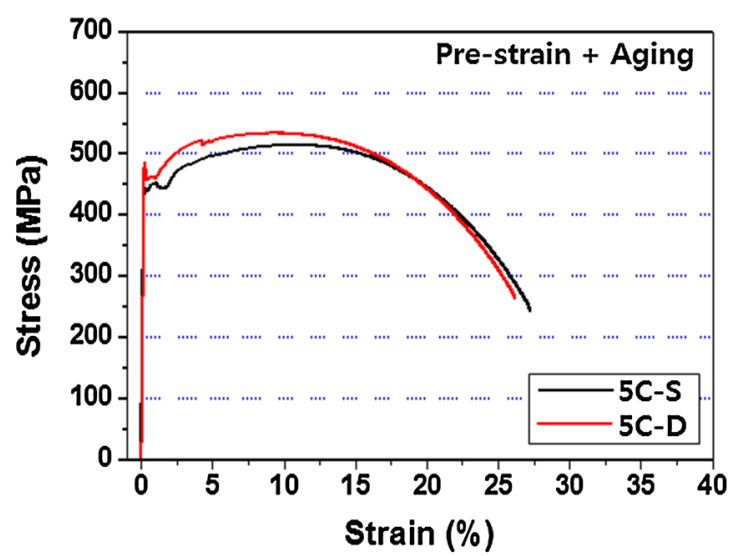

(b)

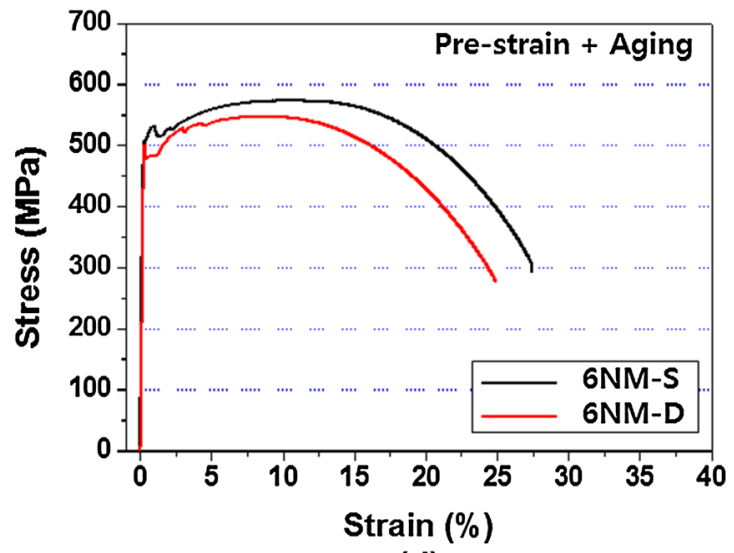

(d)

Fig. 6-Room-temperature engineering stress-engineering strain curves of the $(a) 4 \mathrm{~N},(b) 5 \mathrm{C},(c) 6 \mathrm{NC}$, and $(d) 6 \mathrm{NM}$ steels after 1 pct pre-strain and aging at $473 \mathrm{~K}\left(200{ }^{\circ} \mathrm{C}\right)$.

Table IV. Room-Temperature Tensile Properties of the Steels After 1 Pet Pre-strain and Aging at $473 \mathrm{~K}\left(200{ }^{\circ} \mathrm{C}\right)$

\begin{tabular}{lccccccc}
\hline Steel & $\begin{array}{c}\text { Yield Strength } \\
(\mathrm{MPa})\end{array}$ & $\begin{array}{c}\text { Ultimate Tensile } \\
\text { Strength }(\mathrm{MPa})\end{array}$ & $\begin{array}{c}\text { Uniform } \\
\text { Elongation } \\
(\mathrm{pct})\end{array}$ & $\begin{array}{c}\text { Total Elongation } \\
(\mathrm{pct})\end{array}$ & $\begin{array}{c}\text { Strain } \\
\text { Yield point } \\
\text { Elongation }(\mathrm{pct})\end{array}$ & $\begin{array}{c}\text { Yield } \\
\text { Ratio }\end{array}$ & $\begin{array}{c}\text { Hardening } \\
\text { Exponent }(n \text { value) }\end{array}$ \\
\hline 4N-S & 541 & 576 & 9.2 & 29 & 2.3 & 0.94 & 0.09 \\
5C-S & 445 & 515 & 10.4 & 27 & 1.8 & 0.86 & 0.12 \\
6NC-S & 468 & 534 & 10.0 & 28 & 1.2 & 0.87 \\
6NM-S & 515 & 573 & 10.1 & 28 & 1.3 & 0.90 & 0.10 \\
4N-D & 438 & 491 & 11.4 & 30 & 2.7 & 0.93 & 0.10 \\
5C-D & 457 & 532 & 9.2 & 26 & 1.0 & 0.86 & 0.12 \\
6NC-D & 431 & 502 & 9.8 & 27 & 1.2 & 0.86 & 0.10 \\
6NM-D & 481 & 548 & 8.6 & 25 & & 0.87 & 0.09 \\
\hline
\end{tabular}

which were higher than those of '-D' steels. The uniform elongation and the total elongation of the ' $\mathrm{S}$ ' steels were similar to those of the '-D' steels. The yield point elongation of the $4 \mathrm{~N}$ steel after 1 pct pre-strain and thermal aging at $473 \mathrm{~K}\left(200{ }^{\circ} \mathrm{C}\right)$ was highest at 2.3 to 2.7 pct, whereas the other steels had a low yield point elongation of 1.0 to 1.8 pct. The strain hardening exponent and yield ratio of the steels after 1 pct pre-strain and thermal aging at $473 \mathrm{~K}\left(200{ }^{\circ} \mathrm{C}\right)$ were similar.

\section{DISCUSSION}

The volume fractions of BF and secondary phases increased with increasing carbon content because the $\mathrm{Ar}_{3}$ temperature was reduced. ${ }^{[13,25]}$ When $\mathrm{Cr}$ was added to the strain-based API X60 pipeline steels, the $B_{\mathrm{s}}$ (bainite start temperature), $B_{\mathrm{f}}$ (bainite finish temperature), and $M_{\mathrm{s}}$ (martensite start temperature) decreased. $^{[26]}$ The volume fractions of $\mathrm{PF}$ and $\mathrm{AF}$ increased and evenly distributed fine ferrite grains were 
formed, whereas the volume fractions of $\mathrm{BF}$ and martensite decreased. ${ }^{[16,25]} \mathrm{Ni}$ is an austenite-stabilizing element and effective to improve the strength and toughness without decreasing the weldability and low-temperature toughness. ${ }^{[12}{ }^{\top}$ Although the carbon content of $4 \mathrm{~N}$ steels was low, the steels had high strength and elongation because of the high Ni content. (Table III) Mo improves hardenability of steels and the effect increases more when $\mathrm{B}$ or $\mathrm{Nb}$ is added together. ${ }^{[27,28]}$ Moreover, Mo helps to form low-temperature transformation microstructures, such as BF and martensite, by expanding the carbon-rich regions in the austenite phase. ${ }^{[15,16]}$ In the $4 \mathrm{~N}$ and $5 \mathrm{C}$ steels, the volume fractions of $\mathrm{BF}$ and the secondary phases increased with increasing $\mathrm{C}$ and adding $\mathrm{Cr}$ instead of $\mathrm{Ni}$. In the $5 \mathrm{C}$ and $6 \mathrm{NC}$ steels, the volume fractions of $\mathrm{AF}$ and $\mathrm{BF}$ decreased with increasing $\mathrm{C}$ and adding $\mathrm{Ni}$, whereas the volume fractions of PF and the secondary phases increased. In the $6 \mathrm{NC}$ and $6 \mathrm{NM}$ steels, the volume fraction of $\mathrm{BF}$ was increased by adding $\mathrm{Mo}$ instead of $\mathrm{Cr}$, whereas the volume fractions of $\mathrm{PF}$ and the secondary phases decreased.

Hara et al. ${ }^{[8]}$ reported that high-strain pipeline steels fabricated by a dual-phase rolling process had band structures. In this study, the 'D-' steels fabricated by the dual-phase rolling process contained band structures with elongated PF along the rolling direction, as shown in Figure 4. Many dislocations can be generated in the austenite and PF grains during the dual-phase rolling process; hence, fine-grained PF formed. ${ }^{[29]}$ Therefore, 'D-' steels had a finer effective grain size from 5.2 to $6.6 \mu \mathrm{m}$ than '-S' steels fabricated by a single-phase rolling process. (Table II)

In Table II, the volume fractions of secondary phases in the '-D' steels were higher than those in the '-S' steels. Bainitic steels with high volume fractions of secondary phases showed high uniform elongations because many mobile dislocations were generated between the hard secondary phases and soft microstructures during the tensile test. ${ }^{[20,30]}$ From the tensile properties prior to thermal aging at $473 \mathrm{~K}\left(200{ }^{\circ} \mathrm{C}\right)$ (Table III), the uniform elongation of the '-S' steels with a small volume fraction of secondary phases was low, from 7.6 to 13.1 pct, whereas the uniform elongation of the '-D' steels with a large volume fraction of secondary phases was high, from 12.4 to 16.6 pct. From the tensile properties after thermal aging at $473 \mathrm{~K}\left(200{ }^{\circ} \mathrm{C}\right)$ in Table IV, however, the uniform elongation of the ' $-\mathrm{S}$ ' and '-D' steels were similar, probably because many mobile dislocations were generated in the steels by the deformation of 1 pct pre-strain and the mobile dislocations moved and interacted with the carbon atoms via $s$ thermal aging process, which is called the Cottrell atmosphere. ${ }^{[7,31]}$ When the volume fractions of the low-temperature transformation microstructures, such as AF, BF, and secondary phases were high, many mobile dislocations remained after the Cottrell atmosphere. In the ' $\mathrm{S}$ ' steels, the decrease in the uniform elongation was small, probably because of the many mobile dislocations by the high volume fractions of AF and BF. On the other hand, when the volume fractions of the low-temperature transformation microstructures, such as $\mathrm{AF}, \mathrm{BF}$, and secondary phases, were low, a small amount of mobile dislocations remained after the Cottrell atmosphere. In the '-D' steels, the decrease in the uniform elongation was large probably because of the small number of mobile dislocations by the low volume fractions of AF and BF.

Figure 7 shows the correlation between the $\Delta$ uniform elongation and microstructural factors, such as the volume fractions of $\mathrm{PF}$ and $\mathrm{AF}$ and the effective grain size, in which the $\Delta$ uniform elongation is the difference between the uniform elongation after and before the pre-strain and thermal aging processes. Nagai et $a l .{ }^{[6]}$ reported that the uniform elongation of API X80 pipeline steels after thermal aging was reduced when discontinuous yielding behavior occurred during tensile tests. In this study, all the steels after pre-strain and thermal aging at $473 \mathrm{~K}\left(200{ }^{\circ} \mathrm{C}\right)$ showed discontinuous yielding behavior, hence uniform elongation decreased. The uniform elongation after the pre-strain and thermal aging processes decreased with increasing volume fraction of PF, whereas the uniform elongation after the pre-strain and thermal aging processes increased with increasing volume fraction of AF because many mobile dislocations can be generated near the AF grains by deformation during the tensile tests. According to $\mathrm{Ma}$ et al., ${ }^{[32]}$ mobile dislocations can move parallel to grain boundaries, and even penetrate them when they are thermally activated. Therefore, the fine effective grain size restrained the decrease in uniform elongation, because many mobile dislocations can be generated and migrated when the grains were fine. ${ }^{[33,34]}$

A comparison of the yield point elongation in the tensile properties revealed the '-S' steels to have continuous yielding behavior and low yield point elongation, from 1.7 to 2.9 pct, whereas the '-D' steels showed high yield point elongation, from 2.3 to 5.1 pct. In other words, the portions of the yield point elongation in uniform elongation of the '-D' steels were higher than those of the '-S' steels. After the 1 pct pre-strain and thermal aging processes, the yield point elongation and the uniform elongation of the '-D' steels decreased due to an interaction between a small amount of mobile dislocations with carbon atoms, i.e., the Cottrell atmosphere.

The formation of the mobile dislocation affected the strain hardening exponent. Figure 8 shows the relationship among strain hardening exponent and the volume fraction of PF and AF, and effective grain size. The strain hardening exponent increased with increasing volume fraction of PF, whereas the strain hardening exponent decreased with increasing volume fraction of AF and the effective grain size because the dislocations interacted with carbon atoms during the thermal aging process, i.e., the Cottrell atmosphere. When the volume fraction of PF was high, a small amount of mobile dislocations was generated and interacted with carbon atoms, resulting in an increase in the strain hardening exponent. On the other hand, when the volume fraction of AF was high or the effective grain size was small, a 


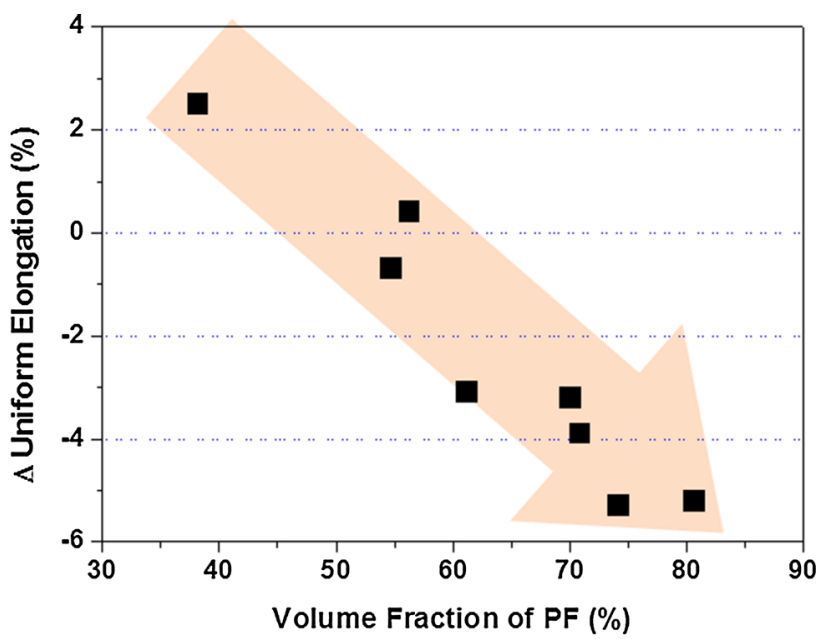

(a)

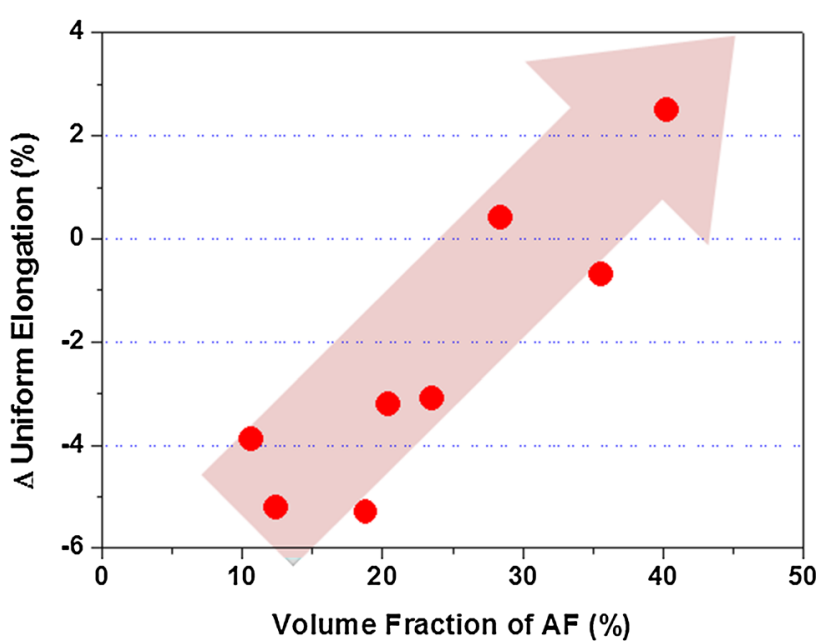

(b)

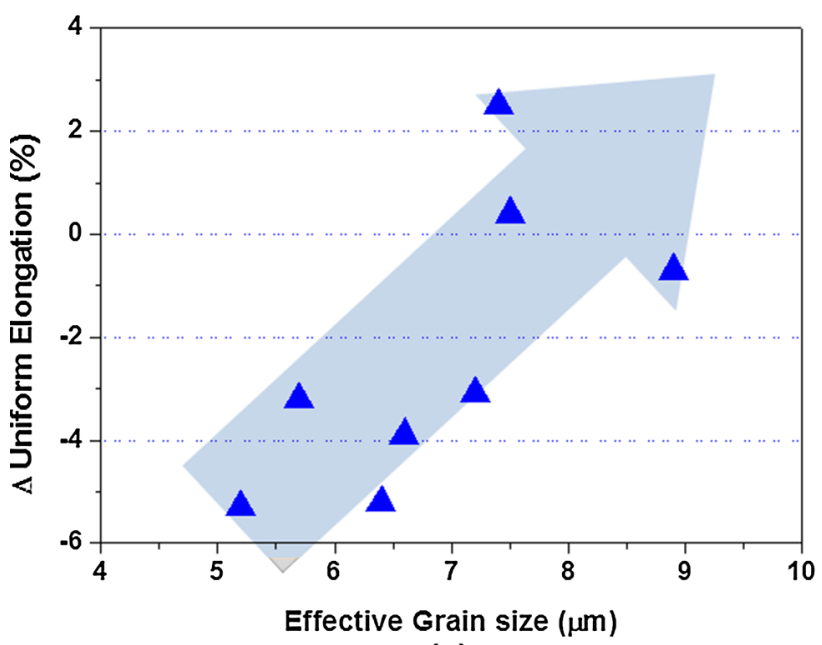

(c)

Fig. 7-Relationship between $\Delta$ uniform elongation and volume fraction of (a) PF and (b) $\mathrm{AF}$, and (c) effective grain size.

large number of mobile dislocations was generated between the AF grains, resulting in an increase in the strain hardening exponent.

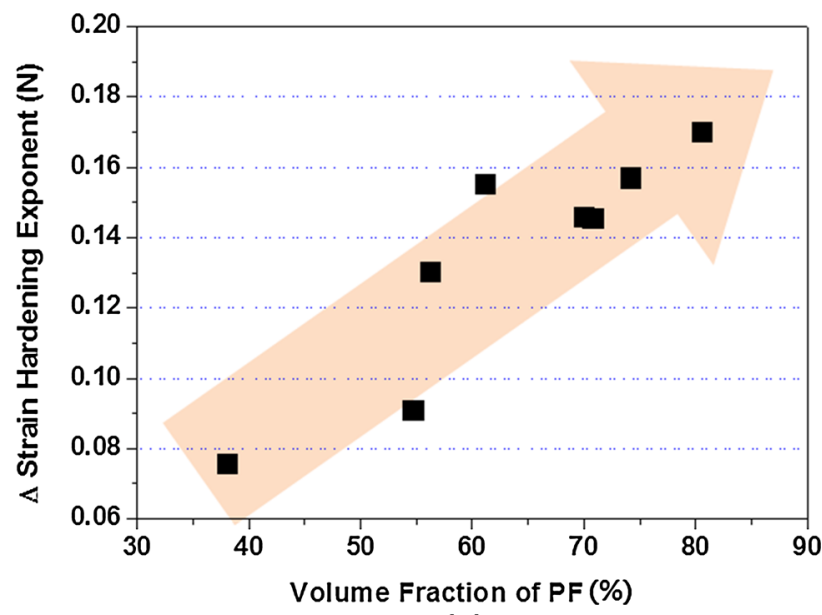

(a)

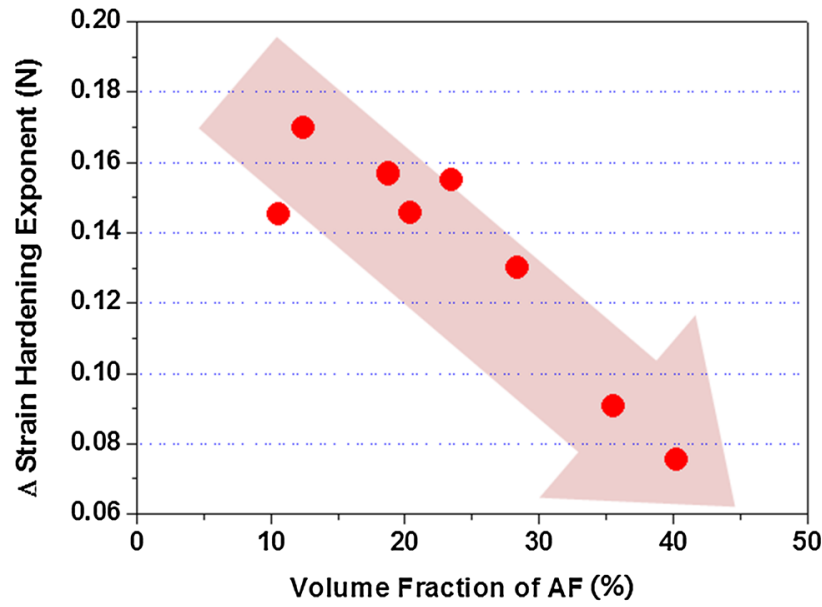

(b)

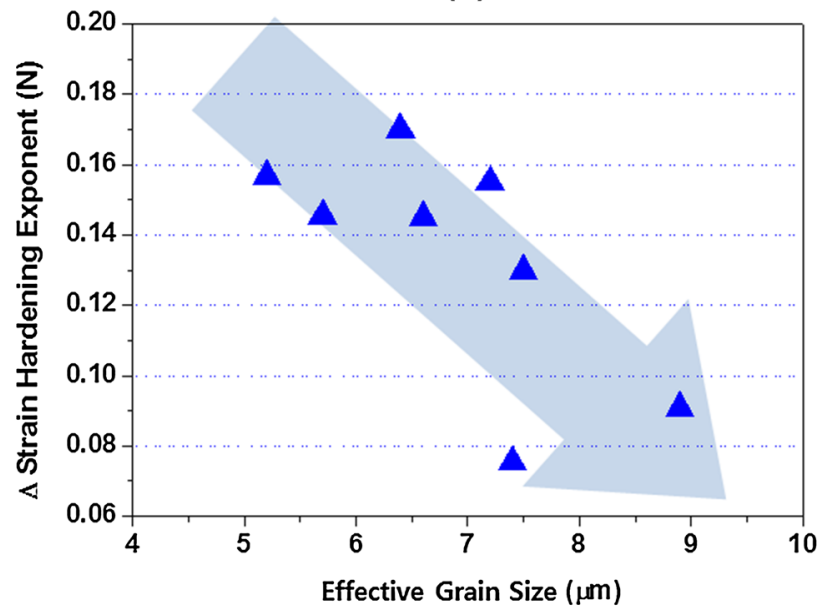

(c)

Fig. 8-Relationship between strain hardening exponent and volume fraction of $(a) \mathrm{PF}$ and $(b) \mathrm{AF}$, and $(c)$ effective grain size.

Figure 9 shows that the inverse pole figure maps, grain boundary maps, and geometrically necessary dislocation (GND) density maps (L-S plane) of the 6NC-D steel were analyzed by EBSD. Kubin and Mortensen ${ }^{[35]}$ suggested that each subboundary contains two perpendicular arrays of screw dislocations based on 

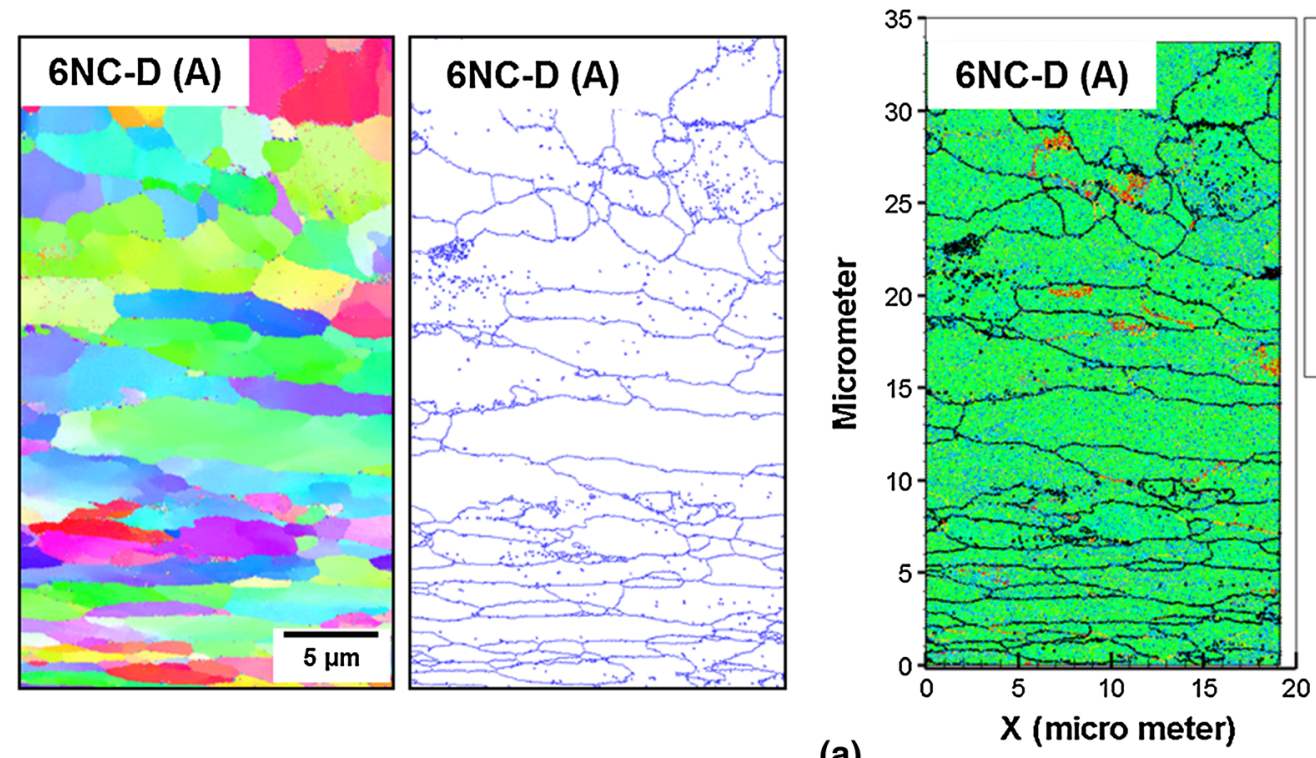

(a)

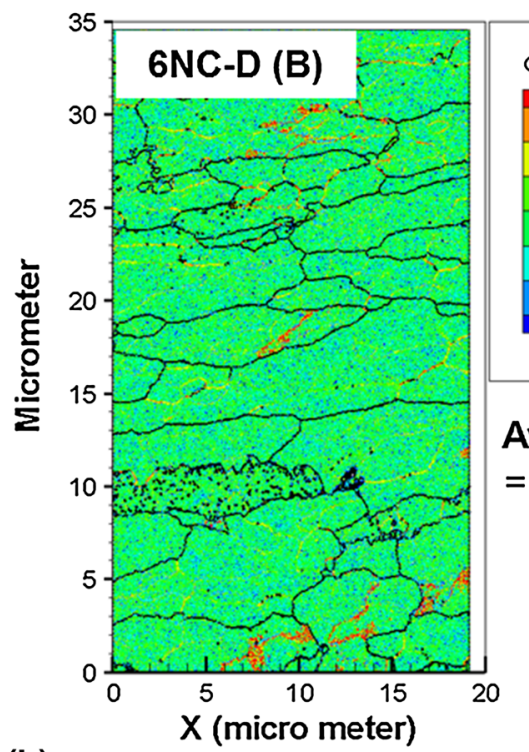

(b)

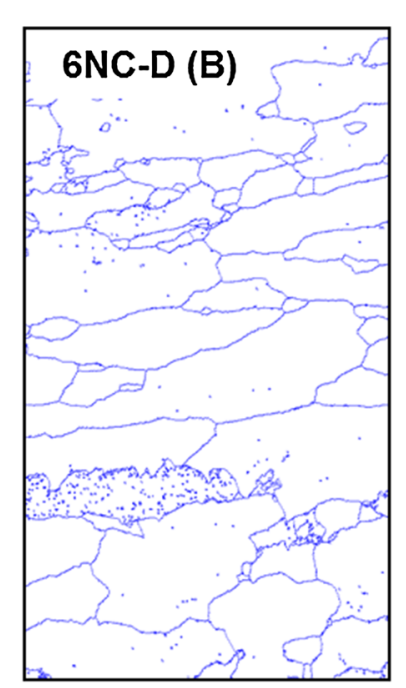

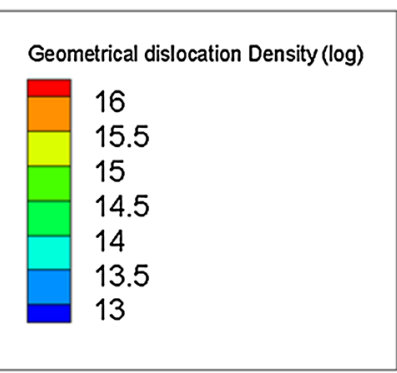

\section{Average GND Density $=3.369 \times 10^{14}$}

Fig. 9-Inverse pole figure maps, grain boundary maps, and geometrically necessary dislocation density maps (L-S plane) of the (a) A and (b) B areas of the 6 NC-D steel.

the strain gradient plasticity model. ${ }^{[36]}$ The average misorientation angle $\theta$ is converted to GND density $\rho_{\mathrm{GND}}$ by the following equation ${ }^{[37]}$ :

$$
\rho_{\mathrm{GND}}=\frac{2 \theta}{u b}
$$

where $u$ is the unit length which came from step size and $\mathrm{b}$ indicates the magnitude of the Burgers vector. We used the kernel average misorientation (KAM) maps to obtain the angle $\theta$ that are constructed by calculation of every measurement point up to its first or second nearest neighbors. From the GND density analysis, the effect of the effective grain size on the GND density was investigated. The average GND density in the A region with a fine effective grain size was $3.369 \times 10^{14}$, whereas the average GND density in the $B$ region with a coarse effective grain size was $2.135 \times 10^{14}$. In other words, the average GND density increased with decreasing effective grain size. Many mobile dislocations can be generated when the effective grain size is small and the volume fraction of AF is high. From the results, it is essential to keep the carbon content below 0.04 wt pet to control the interactions between dislocations and carbon atoms during the thermal aging process in strain-based API X60 pipeline steels. $\mathrm{Cr}$ and $\mathrm{Ni}$ can be used to form fine-grained $\mathrm{AF}$ and a large number of mobile dislocations during deformations. The dual-phase rolling condition helps to improve the low-temperature toughness by fine-grained PF. 


\section{CONCLUSIONS}

Eight types of strain-based API X60 pipeline steels were fabricated by varying the chemical compositions and finish rolling temperatures, and their microstructures were analyzed to examine the correlation between the microstructures and tensile properties of the steels before and after 1 pet pre-strain and thermal aging at $473 \mathrm{~K}\left(200{ }^{\circ} \mathrm{C}\right)$.

1. In the $4 \mathrm{~N}$ and $5 \mathrm{C}$ steels, the volume fractions of $\mathrm{BF}$ and the secondary phases increased with increasing $\mathrm{C}$ and adding $\mathrm{Cr}$ instead of $\mathrm{Ni}$. In the $5 \mathrm{C}$ and $6 \mathrm{NC}$ steels, the volume fractions of $\mathrm{AF}$ and $\mathrm{BF}$ decreased with increasing $\mathrm{C}$ and adding $\mathrm{Ni}$, whereas the volume fractions of PF and the secondary phases increased. In the $6 \mathrm{NC}$ and $6 \mathrm{NM}$ steels, the volume fraction of $\mathrm{BF}$ was increased by adding Mo instead of $\mathrm{Cr}$, whereas the volume fractions of $\mathrm{PF}$ and the secondary phases decreased.

2. In the '-S' steels rolled in the single-phase region, the volume fraction of PF ranged from 40 to $60 \mathrm{pct}$ and the volume fraction of AF ranged from 20 to 40 pct. In the '-D' steels rolled in the dual-phase region, the volume fraction of $\mathrm{PF}$ was more than 70 pct and the volume fraction of AF was below 20 pct. The effective grain size of the '-S' steels was slightly larger than those of the '-D' steels because fine $\mathrm{PF}$ grains $(3 \mu \mathrm{m})$ were formed by the rolling processes in the dual-phase region.

3. The strength of the ' $-\mathrm{S}$ ' steels with a high volume fraction of AF was higher than that of the '-D' steels with a high volume fraction of PF, whereas the yield point elongation and the strain hardening exponent of the '-S' steels was lower than that of the '-D' steels. After the pre-strain and thermal aging processes, all the tensile specimens showed discontinuous yielding behavior. In the '-D' steels after the pre-strain and thermal aging processes, the elongation and strain hardening exponent decreased, whereas the strengths increased.

4. The uniform elongation after the pre-strain and thermal aging processes decreased with increasing volume fraction of PF, whereas the uniform elongation increased with increasing volume fraction of AF. The strain hardening exponent increased with increasing volume fraction of PF, whereas the strain hardening exponent decreased with increasing volume fraction of AF and the effective grain size. Many mobile dislocations can be generated when the volume fraction of AF is high and the effective grain size is small.

\section{ACKNOWLEDGMENTS}

This work was supported by the Ministry of Knowledge Economy under a Grant No. 100400-25, the Ministry of Land, the Infrastructure and Transport under a Grant No. 14IFIP-B067087-02-000000 and the 2013 Research Fund of University of Ulsan.

\section{REFERENCES}

1. R Denys: Pipeline Technology Conference, Elsevier, Amsterdam, 2000, vol. I \& II, pp. 1-166.

2. J.Y. Koo, M.J. Luton, N.V. Bangaru, R.A. Petkovic, D.P. Fairchild, C.W. Petersen, H. Asahi, T. Hara, Y. Terada, M. Sugiyama, H. Tamehiro, Y. Komizo, S. Okaguchi, M. Hamada, A. Yamamoto, and I. Takeuchi: Proc. 13th Int. Offshore Polar Eng. Conf., Honolulu, Hawaii, 2003, pp. 10-18.

3. X-L Yang, Y-B Xu, X-D Tan, and D Wu: Mater. Sci. Eng., A, 2014, vol. 607, pp. 53-62.

4. Y. Shinohara, T. Hara, E. Tsuru, H. Asahi, Y. Terada, and N. Doi: Int. Conf. Offshore Mech. Arctic Eng., OMAE, Halkidiki, Greece, 2005, pp. 27-84.

5. D.B. Lillig: Proc. 18th Int. Offshore Polar Eng. Conf., Vancouver, Canada, 2008, pp. 1-12.

6. K. Nagai, Y. Shinohara, S. Sakamoto, E. Tsuru, and H. Asahi: Proc. 19th Int. Offshore Polar Eng. Conf., Osaka, Japan, 2009, pp. $56-60$.

7. G. Shigesato, Y. Shinohara, T. Hara, M. Sugiyama, and H. Asahi: Proc. 16th Int. Offshore Polar Eng. Conf., Lisbon, Portugal, 2007, pp. 2983-87.

8. T. Hara, Y. Shinohara, Y. Terada, H. Asahi, and N. Doi: Proc. 19th Int. Offshore Polar Eng. Conf., Osaka, Japan, 2009, pp. 73-79.

9. Y. Shinohara, T. Hara, E. Tsuru, and H. Asahi: Proc. 16th Int. Offshore Polar Eng. Conf., Lisbon, Portugal, 2007, pp. 2949-2954.

10. JH Baek, YP Kim, CM Kim, WS Kim, and CS Seok: Mater. Sci. Eng., A, 2010, vol. 527, pp. 1473-79.

11. T. Hara, Y. Shinohara, Y. Hattori, T. Muraki, and N. Doi: Proc. 21th Int. Offshore Polar Eng. Conf., ISOPE, Hawaii, USA, 2011, pp. $575-80$.

12. I Tamura, H Sekine, T Tanaka, and C Ouchi: Thermomechanical Processing of High-Strength Low-Alloy Steels, Butterworth-Heinemann, Oxford, 1988, pp. 80-100.

13. T Sourmail and V Smanio: Acta Mater., 2013, vol. 61, pp. 2639-48.

14. J Speer, DK Matlock, BC De Cooman, and JG Schroth: Acta Mater., 2013, vol. 51, pp. 2611-22.

15. MI Isik, A Kostka, VA Yardley, KG Pradeep, MJ Duarte, PP Choi, D Raabe, and G Eggeler: Acta Mater., 2015, vol. 90, pp. 94-104.

16. ZH Tang and W Stumpf: Mater. Charact., 2008, vol. 59, pp. $717-28$.

17. V. Randle and O. Engler: Introduction to Texture Analysis, CRC Press, Boca Raton, FL, 2014, pp. 153-88.

18. ASTM Standard E8/E8m-13a: Standard Test Methods for Tension Testing of Metallic Materials, ASTM, West Conshohocken, PA, 2013.

19. SW Thompson, DJ Colvin, and G Krauss: Metall. Mater. Trans. $A, 1990$, vol. 21A, pp. 1493-1507.

20. T Araki: Atlas for Bainitic Microstructures, Tokyo, ISIJ, 1992, pp. $1-100$.

21. G Krauss and SW Thompson: ISIJ Int., 1995, vol. 35, pp. 937-45.

22. HKDH Bhadeshia: Mater. Sci. Eng. A, 2004, vol. A378, pp. 34-39.

23. H Ohtani, S Okaguchi, Y Fujishiro, and Y Ohmori: Metall. Trans. $A$, 1990, vol. 21A, pp. 877-88.

24. M Diaz-Fuentes, A Iza-Mendia, and I Gutierrez: Metall. Mater. Trans. A, 2003, vol. 34A, pp. 2505-16.

25. BL Bramfitt and JG Speer: Metall. Trans. A, 1990, vol. 21A, pp. 817-29.

26. FG Caballero, MK Miller, C Garcia-Mateo, J Cornide, and MJ Santofimia: Scripta Mater., 2012, vol. 27, pp. 846-49.

27. WB Lee, SG Hong, CG Park, KH Kim, and SH Park: Scripta Mater., 2000, vol. 43, pp. 319-24.

28. H Asahi: ISIJ Int., 2002, vol. 42, pp. 1150-55.

29. M Calcagnotto, Y Adachi, D Ponge, and D Raabe: Acta Mater., 2011, vol. 59, pp. 658-70. 
30. D Hull and DJ Bacon: Introduction to Dislocations, 5th ed., Elsevier Ltd., Amsterdam, 2011, pp. 1-272.

31. AH Cottrell: Trans. Am. Inst. Mech. Eng., 1958, vol. 212, pp. 192-203.

32. A Ma, F Roters, and D Raabe: Acta Mater., 2006, vol. 54, pp. 2181-94.

33. NJ Kim and G Thomas: Scripta Metall., 1984, vol. 18, pp. 817-20.
34. RT Li, XR Zuo, YY Hu, ZW Wang, and DX Hu: Mater. Charact., 2011, vol. 62, pp. 801-06.

35. LP Kubin and A Mortensen: Scripta Mater., 2003, vol. 48, pp. 119-25.

36. H Gao, Y Huang, WD Nix, and JW Hutchinson: J. Mech. Phys. Solids, 1999, vol. 47, pp. 1239-63.

37. M Calcagnotto, D Ponge, E Demir, and D Raabe: Mater. Sci. Eng., A, 2010, vol. 527, pp. 2738-46. 